are in qualitative, descriptive form and, in four different languages. It is the research team's aim to express as much of the data in quantitative form as can be reliably accomplished.

The final CLIWOC database will be linked to that of COADS and will include daily observations from many of the World's major oceanic areas. Figure 1 shows the more frequented sea routes of the period and, consequently, those areas where more information will be available. The data will be presented in a processed form using terms conforming to presentday usage and understanding. Information will be based on the most frequently recorded elements of wind strength and direction but data can also be provided on a wider range of commonly recorded phenomena that include rain and snow, thunder, fog and even the incidence of sea ice cover. To render the database more manageable, annual and decadal summaries will be included. A metadatabase will also allow users to consult the original sources.

While the primary objective of this project is the preparation and dissemination of a daily climatic database for the century 1750 to 1850 , other valuable outcomes will also be achieved. Not least of these is the insight that the logbook information will give to the question of climatic change over oceanic areas. It should be emphasized that no other source provides a basis on which to examine such variation at a daily scale. This unique opportunity will be exploited to its fullest potential while not overlooking the importance of longer term trends in climatic behavior.
CLIWOC partners wish to share their experience with colleagues interested in similar research fields. A workshop is therefore planned for spring 2002 in the Netherlands to host scientists from a variety of fields: climatologists, meteorologists, historians, archivists, geographers and other academics who appreciate the role of historical documents in climatic research.

Further information about CLIWOC can be found at the project web-site: http://www.ucm.es/info/cliwoc/

\section{REFERENCES}

Díaz H and S. D. Woodruff (eds), 1999, Proceedings of the International Workshop on Digitation and Preparation of Historical Marine Data and Metadata (Toledo, Spain, 15-17 September 1997), WMO/ TD-N 957.

Manabe, T. , 1999, 'The Digitized Kobe Collection, Phase I: Historical Surface Marine Meteorological Observations in the Archive of the Japan Meteorological Agency', Bulletin of the American Meteological Society, № 12, 80, 2703-2715.

\title{
Paleo-Grassland Research (PGR) 2000: a Conference on the Reconstruction and Modeling of Grass-Dominated Ecosystems
}

\author{
Connecticut, USA, 1-3 June 2000
}

Since any single proxy of past vegetation often lacks taxonomic resolution and subsequent ecophysiological information, paleoecological reconstruction and modeling of grassdominated ecosystems is reliant on the information supplied by multiple disciplines and the analysis of multiple proxies. Proficiency in a single proxy demands years of training, thus the success of a multi-proxy approach requires collaboration. The first Paleo-Grassland Research 2000 (PGR2000) workshop in Westbrook, Connecticut fostered such collaboration by bringing together over forty participants, representing twelve countries within North and South America, Europe, Asia and Africa. The primary goals of the meeting were to 1) promote inter-disciplinary collaborative research; 2) to synthesize an informed multi-proxy approach to the reconstruction of past grasslands; 3) establish a network of scientists concerned with grassland paleoecology.

Funding for PGR2000 was provided by the National Science Foundation-Paleoclimate Program and PAGES - Past Global Changes.

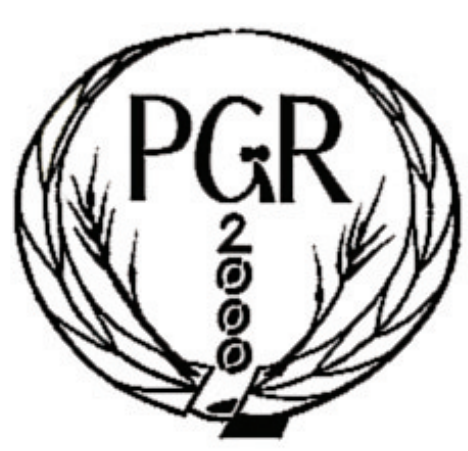

poster session. The size and structure of the workshop allowed delegates to attend all sessions.

\section{Overview Session}

The conference opened with an introductory session with presentations by Matthew Wooller (Carnegie Institution of Washington, USA), Thure Cerling (University of Utah, USA) and Jim Ehleringer (University of Utah, USA) who introduced some fundamental physiological features of the grass family. John Kingtson (Yale University, USA) provided a synthesis of data derived from multiple proxy evidence on the origins of grasslands, while Dan Livingstone (Duke University, USA) introduced grass cuticles, an under-utilized proxy of past grasslands, and discussed issues concerned with their taphonomy.

\section{Pollen and Modeling Session}

The second session was devoted to palynological research and included evidence from South America, including a presentation by Mark Bush (Florida Institute of Technology, USA) on Amazonian pollen sequences 


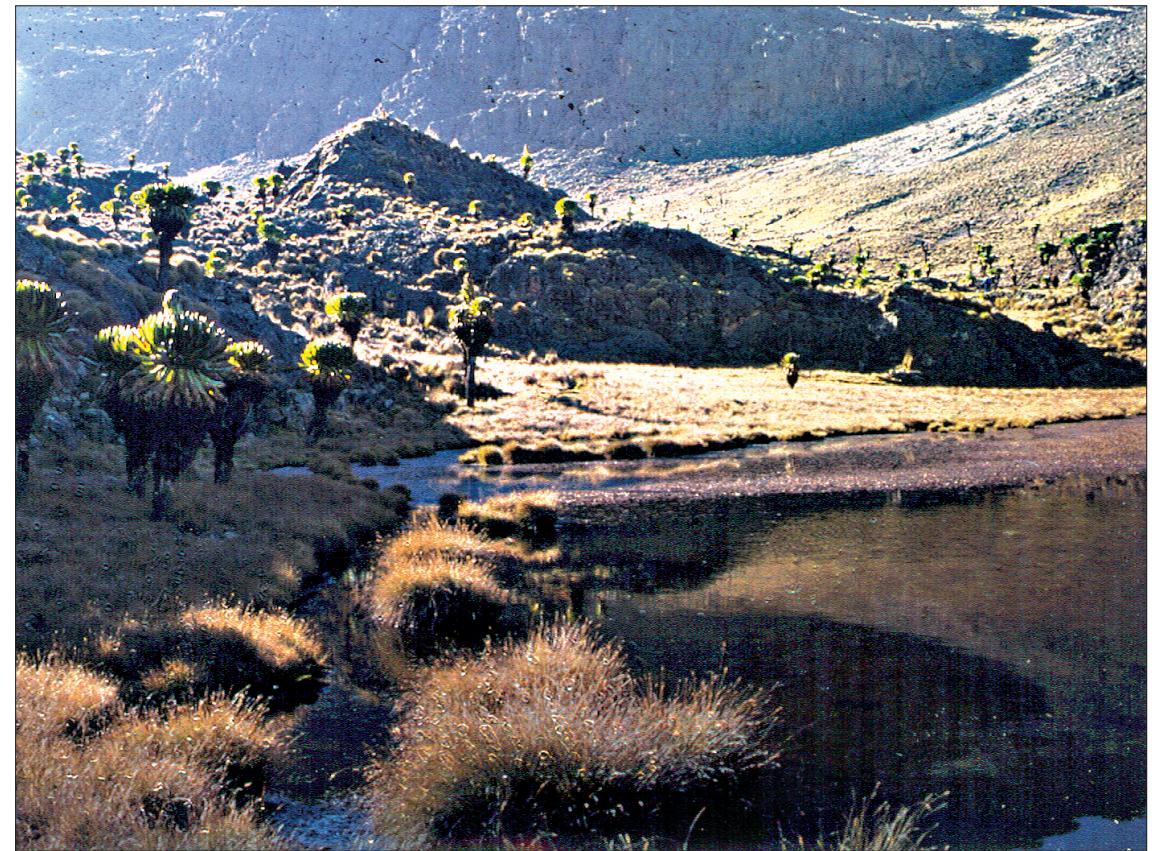

A grass dominated ecosystem at high altitude ( 4000 m.a.s.I.) on Mount Kenya, East Africa. Photograph taken by Matthew Wooller.

and Hermann Behling (Zentrum für MarineTropenökologie, Germany) on Late Quaternary Brazilian grasslands. Raymonde Bonnefille (CEREGE, France) presented pollen evidence, alongside other proxies, of East African vegetation since the tertiary, while Louis Scott (University of the Orange Free State, RSA) presented pollen and charcoal evidence related to grassland development in South Africa during the Late Quaternary. Cathy Hoyt presented evidence of Late Quaternary grassland change in North America. Since pollen from different grass species is morphologically identical, the presentations by palynologists emphasized the need for additional proxies of past grasslands with which to compare pollen data.

\section{Phytoliths Session}

The particles of biogenic silica produced in the leaves of grasses, known as phytoliths, have greater morphological variation than grass pollen and are an effective resource for grassland reconstruction. Phytolith research was presented by Irwin Rovner (North Carolina State University, USA), Anne Alexandre (CEREGE, France) and Glen Fredlund (University ofWisconsin-Milwaukee, USA) during the morning of the second day. Caroline Strömberg (UC Museum of Paleontology, USA) discussed grassdominated biomes in the late Tertiary of North America and related this to faunal evolution, complementing Bruce MacFadden's (Florida Museum of Natural History, USA) approach to reconstructing Pleistocene vegetation using evidence from the faunal record. Phytolith data was also presented by Mikhail Blinnikov (St. Cloud State University, USA) who produced a reconstruction of the late-Pleistocene grasslands of the Columbia river basin, USA and Francesca Smith (INSTAAR, USA) who provided an interdisciplinary study of stable carbon isotopes ratios preserved in fossil phytoliths.

\section{Isotopes and Other Techniques}

The final oral session allowed Alayne Street-Perrott, David Swain and Katherine Ficken to present the multi-proxy approach applied by the Tropical Palaeoenvironments Research Group (University of Wales Swansea, UK) and included results from vegetation modelling along with pollen, compound specific isotope and grass cuticle data derived from crater lakes on Mount Kenya, East Africa. Arnoud Boom (University of Amsterdam, The Netherlands) and Robert Marchant (University of Amsterdam, The Netherlands) provided bulk carbon isotopic and pollen evidence from the high plain of Bogota, South America, while Yongsong Huang (Brown University, USA) presented compound specific isotope data from Mesoamerica.
Kristina Beuning (Wesleyan University, USA) presented the final talk, showing her work involving stable carbon isotope analyses of pollen.

\section{Additional Activities}

A poster session occupied part of the afternoon on the second day and allowed delegates to examine approximately twelve posters related to paleo-grassland research. Activities on the second day concluded with delegates meeting to discuss future research prospects in areas of common geographical interest. Students from Wesleyan University, including Jessica Scott, Rehanna Chaudhri and Festo Lugolobi assisted throughout the conference. The meeting concluded with an open discussion on the future of Paleo-Grassland Research. Perfect weather conditions, booked by the organizers, allowed the meeting to end with a beautiful sunset observed from aboard a $32 \mathrm{ft}$ Schooner sailboat on Long Island Sound.

\section{Outputs}

The primary outcomes of this workshop are: 1) a forthcoming collection of peer-reviewed articles to appear in Palaeoclimate Data and Modelling, documenting research involving the current state-of-theart techniques for paleo-grassland research; 2) a PGR 2000 website (http://www.wesleyan.edu/ kbeuning/ PGR2000); 3) a listserver to facilitate collaboration by keeping members of various disciplines and geographic regions connected (to subscribe contact kbeuning@wesleyan.edu); 4) plans for a future meeting in 2002 to be held in either India or Texas, USA ; 5) the formulation of the Paleo-Grassland Research Association (PGRASS): a working group aiming to reconstruct global grassland evolution and response to climate, herbivory, fire and human activities

\section{Matthew J. Wooller}

Geophysical Laboratory, Carnegie Institution of Washington, DC, USA

wooller@gl.ciw.edu

\section{KRISTina R. Beuning}

Department of Earth and Environmental Sciences, Wesleyan University, CT, USA

kbeuning@wesleyan.edu 